Revista Iberoamericana de las Ciencias Biológicas y Agropecuarias

https://doi.org/10.23913/ciba.v9i17.96

Artículos Científicos

\title{
Antagonismo de microorganismos nativos sobre Phytophthora infestans (Mont.) de Bary aislada de Solanum tuberosum L.
}

Antagonism of Native Microorganisms on Phytophthora Infestans (Mont.) de Bary Isolated from Solanum Tuberosum $L$.

Antagonismo de microrganismos nativos em Phytophthora infestans (Mont.) De Bary isolado de Solanum tuberosum $L$.

Citlalli Harris Valle Instituto Tecnológico Superior de Zacapoaxtla, Puebla, México citlalliharris@yaho.com.mx https://orcid.org/0000-0001-9353-0796

Efren Bonilla Pioquinto Instituto Tecnológico Superior de Zacapoaxtla, Puebla, México bonilla_08@hotmail.com https://orcid.org/0000-0002-5408-5375

Martín Palafox Rodríguez Instituto Tecnológico Superior de Zacapoaxtla, Puebla, México martinpalafox@msn.com https://orcid.org/0000-0002-0988-4282 
Revista Iberoamericana de las Ciencias Biológicas

\section{y Agropecuarias}

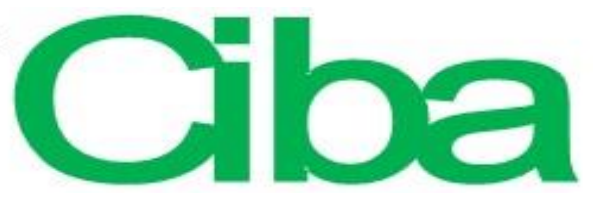

\section{Resumen}

El manejo inadecuado de las enfermedades en cultivos de la papa origina que algunas especies patógenas generen resistencia a diversos plaguicidas. Esto incrementa el uso de agroquímicos que ocasionan contaminación en el suelo y el agua, lo cual daña la salud humana. Phytophthora infestans (Mont.) de Bary (causante del tizón tardío) limita la producción de papa (Solanum tuberosum L.) y provoca pérdidas económicas importantes. Este tubérculo se produce en la región nororiental de Puebla, México, y está documentada la presencia de tizón tardío, el cual es controlado con la aplicación de fungicidas sintéticos. En el presente estudio se evaluó la inhibición antagónica in vitro de dos microorganismos nativos (Trichoderma sp. y Pseudomona sp.), aislados de la rizósfera de una solanácea silvestre (en las inmediaciones de un cultivo de papa), sobre el desarrollo de $P$. infestans procedente de plantas infectadas. Se hicieron pruebas utilizando a los antagonistas de manera independiente y en combinación. Y se determinó el efecto del antagonista sobre el patógeno con base en el porcentaje de inhibición de crecimiento radial, en el caso del hongo el tipo de interacción hifal, la capacidad y forma antagónicas. Se observó que el hongo puede inhibir indirectamente el crecimiento de $P$. infestans (alrededor de $50 \%$ ), mientras que la inhibición directa con ambos microorganismos evaluados por separado es de más de $65 \%$. El tratamiento utilizando la combinación de Pseudomona-Trichoderma disminuyó el crecimiento en mayor proporción (80 \%-92 \%) que cualquiera de los antagonistas evaluados de manera independiente. A pesar de que la bacteria disminuye el crecimiento del hongo antagonista, Trichoderma sp. produce compuestos que afectan indirectamente al fitopatógeno, lo que origina un efecto sinérgico entre los dos microorganismos nativos para disminuir el desarrollo del patógeno en cultivos in vitro. Se considera importante diseñar una estrategia para la utilización de microorganismos presentes en los suelos de la región (nativos) como agentes que reduzcan la incidencia de tizón tardío.

Palabras clave: control biológico, Pseudomona sp., tizón tardío, Trichoderma sp. 
Revista Iberoamericana de las Ciencias Biológicas y Agropecuarias

\section{Abstract}

The inadequate management of diseases in potato crops causes some pathogenic species to generate resistance to various pesticides, which increases the use of agrochemicals that cause pollution in soil and water, damaging human health. Phytophthora infestans (Mont.) de Bary (cause of late blight) limits the potatoes production (Solanum tuberosum L.) and causes significant economic losses. Potato is produced in the northeast region of Puebla, Mexico, and the presence of late blight is documented, which is controlled with the application of synthetic fungicides. In this study, the antagonist inhibition in vitro of two native microorganisms (Trichoderma sp. and Pseudomonas sp.) isolated from the rhizosphere of a wild Solanaceae (in the vicinity of a potato crop), was evaluated on $P$. infestans obtained from infected plants. Tests were performed using the antagonists independently and in combination. The effect of the antagonist on the pathogen was determined based on the percentage of radial growth inhibition, in the case of the fungus the type of hyphal interaction, the antagonistic capacity and form. The results show that the fungus can indirectly inhibit the growth of $P$. infestans (around 50\%), while the direct inhibition, with both microorganisms evaluated separately, is more than $65 \%$. The treatment using the combination of Pseudomona-Trichoderma decreased the growth in greater proportion (80\%-92\%) than any of the antagonists evaluated independently. Although the bacterium decreases the growth of the antagonist fungus, Trichoderma sp. produces compounds that indirectly affect the phytopathogen, causing a synergistic effect between the two native microorganisms to decrease the development of the pathogen in vitro cultures. We consider it is important to design a strategy to use native microorganisms present in the soils of the region as agents that reduce the incidence of late blight.

Keywords: biological control, Pseudomona sp., late blight, Trichoderma sp. 
Revista Iberoamericana de las Ciencias Biológicas

\section{y Agropecuarias}

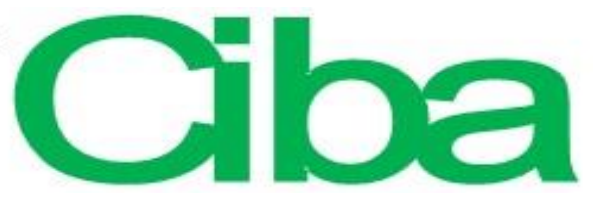

\section{Resumo}

O manejo inadequado de doenças nas culturas de batata faz com que algumas espécies patogênicas gerem resistência a vários pesticidas. Isso aumenta o uso de agroquímicos que causam contaminação no solo e na água, o que prejudica a saúde humana. Phytophthora infestans de Bary (Mont.) (A causa da praga tardia) limita a produção de batata (Solanum tuberosum L.) e causa perdas econômicas significativas. Esse tubérculo é produzido na região nordeste de Puebla, México, e a presença de ferrugem tardia é documentada, a qual é controlada com a aplicação de fungicidas sintéticos. No presente estudo, avaliou-se a inibição antagonista in vitro de dois microrganismos nativos (Trichoderma sp. E Pseudomona sp.), Isolados da rizosfera de um solanum selvagem (nas proximidades de uma cultura de batata), no desenvolvimento de P. infestans de plantas infectadas. Os testes foram realizados usando os antagonistas independentemente e em combinação. E o efeito do antagonista no patógeno foi determinado com base na porcentagem de inibição do crescimento radial; no caso do fungo, o tipo de interação hifal, a capacidade e a forma antagônicas. Observou-se que o fungo pode inibir indiretamente o crescimento de P. infestans (cerca de 50\%), enquanto a inibição direta com os dois microrganismos avaliados separadamente é superior a $65 \%$. O tratamento usando a combinação Pseudomone-Trichoderma diminuiu o crescimento em uma proporção maior (80\% -92\%) do que qualquer um dos antagonistas avaliados independentemente. Embora a bactéria retarde o crescimento do fungo antagonista, Trichoderma sp. Produz compostos que afetam indiretamente o fitopatógeno, o que causa um efeito sinérgico entre os dois microrganismos nativos para diminuir o desenvolvimento do patógeno em culturas in vitro. Considera-se importante elaborar uma estratégia para o uso de microrganismos presentes nos solos da região (nativos) como agentes que reduzem a incidência de queima tardia.

Palavras-chave: controle biológico, Pseudomona sp., Ferrugem tardia, Trichoderma sp.

Fecha recepción: Julio 2019

Fecha aceptación: Diciembre 2019 
Revista Iberoamericana de

las Ciencias Biológicas

y Agropecuarias

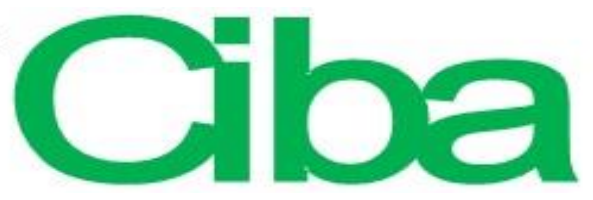

ISSN: 2007 - 9990

\section{Introducción}

Los cultivos de papa (Solanum tuberosum L.) son atacados por hongos fitopatógenos, tanto en cosecha como en poscosecha, principalmente en regiones con clima húmedo (Pérez y Forbes, 2008). Para disminuir los daños ocasionados por las enfermedades fúngicas se utilizan agroquímicos (fungicidas) que a su vez disminuyen la calidad de los alimentos, contaminan el suelo y el agua (Badii y Varela, 2015).

El cultivo de papa ocupa el cuarto lugar entre los alimentos de mayor consumo en el mundo y su producción es de 320 millones de toneladas al año (Borba, 2008). No obstante, su producción se limita por el ataque de Phytophthora infestans (en adelante P. infestans), causal del tizón tardío. La manera tradicional de controlar esta enfermedad es utilizando compuestos químicos que contaminan y ocasionan que $P$. infestans desarrolle resistencia, por ejemplo, el metalaxyl (Romero, Lozoya, Mora, Fernández y Grünwald, 2012).

Debido a los inconvenientes en los sistemas de producción tradicional (utilizando agroquímicos), se ha optado por buscar alternativas de control de enfermedades fúngicas mediante microorganismos que actúan como antagónicos de dichos patógenos (Aguado, Rascón y Luna, 2012; Altieri y Nicholls, 2008).

Trichoderma es un género con especies catalogadas como agentes de control biológico, impide que los hongos fitopatógenos provoquen daños en las raíces y partes aéreas de la planta. Actúa mediante mecanismos directos como el micoparasitismo o la competencia por espacio y nutrientes; también puede desarrollar estrategias de inhibición indirecta como la antibiosis (síntesis de metabolitos tóxicos o antibióticos de naturaleza volátil o no volátil), la estimulación del crecimiento (solubiliza nutrientes y activa fitohormonas) y la inducción de resistencia sistémica (González y Reséndiz, 2012).

El género Pseudomona incluye bacterias saprófitas promotoras del crecimiento de la planta, con actividad biopesticida, biofungicida y biofertilizante. Sus mecanismos para el control biológico de enfermedades fúngicas son similares a los del Trichoderma (Cano, 2011; Hernández, Heydrich, Velázquez y Hernández, 2006)

Martínez y Osorio (2007) encontraron que biosurfactantes producidos por Pseudomona fluorescens reducen hasta $60 \%$ la incidencia de $P$. infestans en papa, sin que inhiban el desarrollo de otros hongos y bacterias del suelo. En cultivos de tomate (Lycopersicon esculentum 
Revista Iberoamericana de las Ciencias Biológicas

\section{y Agropecuarias}

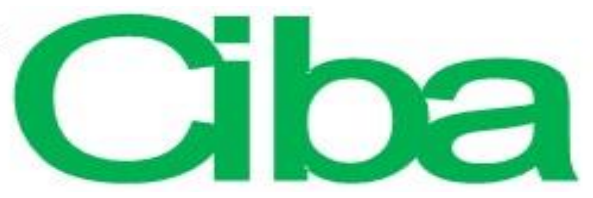

Mill.) se observó que diferentes cepas de Trichoderma inhamatum inhiben el crecimiento in vitro de $P$. infestans y reducen la incidencia del fitopatógeno en campo (Puño et al., 2001).

Paucarima et al. (2014) evaluaron el efecto potencial de microorganismos considerando su origen, y encontraron que los nativos antagónicos y promotores de crecimiento (Bacillus spp., Pseudomonas fluorescens y Burkholderia cepacia) inhiben el desarrollo de Rhizoctonia solani y $P$. infestans en papa. En otro estudio se evaluaron 10 diferentes cepas de Trichoderma en el control de $P$. infestans y Sclerotinia sp.; aquí observaron que las cepas nativas tienen mayores posibilidades de adaptabilidad y éxito en comparación con las cepas disponibles actualmente de manera comercial (García et al., 2017)

Los antecedentes revisados sugieren que Trichoderma sp. y Pseudomona sp. son una alternativa para disminuir el daño causado por el tizón tardío, por lo que se aislaron dichos microorganismos antagónicos a partir de solanáceas silvestres, en las inmediaciones de campos de cultivo de papa, para evaluar la inhibición in vitro directa e indirecta (utilizándolos por separado o simultáneamente) sobre $P$. infestans, también originario de la región, aislado de un cultivo local de papa infectada con tizón tardío en Zacapoaxtla, Puebla, México.

\section{Materiales y métodos}

$P$. infestans se aisló a partir de tejido en cultivos de papa con síntomas de infección por tizón tardío en la localidad de Xaltetela, Zacapoaxtla, en el estado de Puebla, México. El material vegetal fue colectado por muestreo dirigido: se tomaron partes con síntomas de infección en hojas, tallos y pecíolos; estos fueron depositados en bolsas de plástico transparente $(14 \mathrm{x} 20 \mathrm{~cm})$. En el laboratorio las muestras se depositaron en cajas de Petri sobre papel filtro húmedo y se dejaron 24 horas a temperatura ambiente. Fragmentos de $2 \mathrm{~cm}^{2}$ de tejido infectado se sumergieron en etanol a $70 \%$ durante 1 minuto, y en hipoclorito a $3 \%$ por 30 segundos. Los fragmentos fueron depositados en agar nutritivo e incubados durante 8 días a $25{ }^{\circ} \mathrm{C}$ en la oscuridad (Fernández et al., 2005). La identificación y descripción de las características morfológicas se hizo con base en lo recopilado por Erwin y Ribeiro (1996).

Para el aislamiento de antagonistas nativos se muestreó una solanácea silvestre cercana a un cultivo de papa en la localidad de Ixticpac, Zacapoaxtla, Puebla. La recolección de la muestra (200 g de sustrato) se realizó en el suelo que rodea las raíces a una profundidad de 5-10 cm. El 
Revista Iberoamericana de las Ciencias Biológicas

\section{y Agropecuarias}

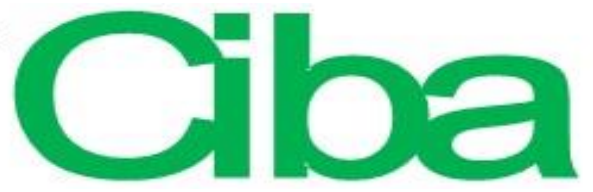

sustrato se trasladó en bolsas plásticas a laboratorio y fue guardado a $4{ }^{\circ} \mathrm{C}$ hasta su procesamiento.

Para aislar Trichoderma sp. se empleó el protocolo modificado descrito por Kim et al. (2003). El suelo (10 g) se homogeneizó en $90 \mathrm{ml}$ de agua destilada y esterilizada (retirando fragmentos de raíces, madera y piedras); se colocó en agitación de tres a cinco minutos. Se realizaron las disoluciones seriadas $10^{-2}$ y $10^{-5} \mathrm{~g} / \mathrm{ml}$ y se sembraron en medio papa-dextrosa-agar (PDA); se incubó a $28{ }^{\circ} \mathrm{C}$ durante 8 días. Para la determinación de las características macroscópicas se hicieron cultivos en placa durante 14 días, se evaluó el color de la colonia (anverso y reverso), la forma y la textura. La identificación y descripción de las características microscópicas se hizo con microcultivos observando conidios (forma, pigmentación y ornamentación), conidióforos (tipo eje central, características de las ramificaciones, formación de pústulas), fiálides (forma agrupación presencia/ausencia fiálides intercalares) y clamidosporas (unicelular/multicelulares), con base en una clave taxonómica para Trichoderma y Gliocladium (Kubicek y Harman, 1998). Se utilizó un microscopio óptico marca Zeiss con cámara fotográfica integrada.

Para aislar e identificar cepas de Pseudomonas se homogeneizaron $10 \mathrm{~g}$ de suelo (retirando fragmentos de raíces, madera y piedras) en $90 \mathrm{ml}$ de agua-peptona a $0.1 \%$ estéril; se agitó entre tres y cinco minutos. Se realizaron disoluciones seriadas $\left(10^{-2}-10^{-5} \mathrm{~g} / \mathrm{ml}\right)$ y de las dos últimas disoluciones se tomaron $100 \mu \mathrm{m}$ para sembrarlo por duplicado en agar nutritivo. Los cultivos fueron incubados a $28^{\circ} \mathrm{C}$ durante 24 horas. Para la identificación de las cepas de Pseudomonas $s p$. se utilizó el protocolo propuesto por Helguero (2010) y Burkholder (1957).

El antagonismo in vitro de las cepas de Trichoderma sp. versus P. infestans se comprobó mediante el método de cultivo dual en medio PDA. En las cajas de Petri se colocaron dos segmentos de cultivo a $70 \mathrm{~mm}$ de distancia: en un extremo un disco de $1 \mathrm{~cm}$ de diámetro de agar con micelio de $P$. infestans y en el extremo opuesto otro disco del mismo tamaño con micelio de Trichoderma sp. Para el testigo solo se añadió un disco de medio con P. infestans en un extremo. Se incubaron a $28{ }^{\circ} \mathrm{C}$ y se midió el crecimiento radial del micelio del patógeno cada 24 horas. Con los datos se calculó el porcentaje de inhibición.

Se evaluó la capacidad antagónica in vitro (con escala del uno al cinco) de Trichoderma sp. sobre el patógeno según la extensión del micelio del antagonista con referencia al testigo (Bell, Wells y Markaman, 1982) y la forma de antagonismo (físico, químico, hiperparasitario o físico- 
Revista Iberoamericana de las Ciencias Biológicas

\section{y Agropecuarias}

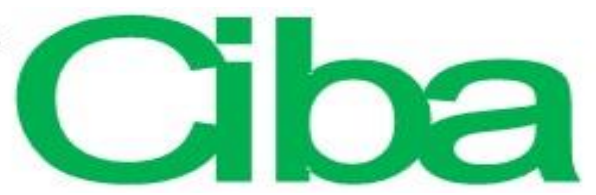

químico) según la zona de contacto entre los organismos y la intensidad en porcentaje (Davet, Artigues y Martin, 1981). Para determinar el tipo de interacción hifal (enrollamiento, penetración, vacuolización o lisis) se utilizaron microcultivos (Riddell, 1950).

El efecto indirecto de Trichoderma sp. en la inhibición del crecimiento micelial de $P$. infestans se realizó con el protocolo descrito por Dennis y Webster (1971). El proceso consistió en agregar $8 \mathrm{ml}$ de medio PDA en ambas tapas de las cajas de Petri de $90 \mathrm{~mm}$ de diámetro. En la tapa superior se colocó un disco de $1 \mathrm{~cm}$ de diámetro de agar que contenía el micelio de $P$. infestans, y en la tapa inferior se añadió otro disco de agar con micelio de la cepa de Trichoderma sp., posteriormente se colocaron las dos tapas una frente a la otra y se sellaron; para el testigo solo se usó un disco de agar sin microorganismos (limpio) en lugar del antagonista. Las placas se incubaron a $28^{\circ} \mathrm{C}$ y cada 24 horas se midió el crecimiento del patógeno en la caja testigo y en el tratamiento. Con los datos se calculó el porcentaje de inhibición.

El antagonismo in vitro de las cepas de Pseudomonas sp. versus P. infestans se comprobó cultivando en agar nutritivo. La bacteria fue sembrada por un estriado sobre toda la caja con la cepa de Pseudomonas sp. y en el centro se colocó un disco de $1 \mathrm{~cm}$ de diámetro de agar que contenía el micelio de $P$. infestans. Para el testigo solo se añadió un disco de agar con micelio de P. infestans en ausencia del estriado de Pseudomonas sp. Luego los cultivos se incubaron a $28^{\circ} \mathrm{C}$ y cada 24 horas se midió el crecimiento radial de $P$. infestans y se comparó con el crecimiento radial del patógeno en las cajas testigo. Conjuntamente se calculó el porcentaje de inhibición de crecimiento radial.

Para determinar la inhibición in vitro de Trichoderma sp. en combinación con Pseudomona sp. sobre $P$. infestans, se sembró Pseudomonas sp. en PDA realizando un estriado sobre toda la superficie, en un extremo se colocó un disco de $1 \mathrm{~cm}$ de diámetro de agar con micelio Trichoderma sp. y en el otro extremo se colocó otro disco con micelio de P. infestans. Para el testigo solo se añadió un disco de agar con micelio de $P$. infestans en ausencia de los antagonistas. Posteriormente los cultivos se incubaron a $28{ }^{\circ} \mathrm{C}$ y cada 24 horas se midió el crecimiento radial de $P$. infestans en el testigo y del tratamiento. Con los datos se calculó el porcentaje de inhibición del patógeno.

En todas las pruebas de antagonismo se obtuvo el porcentaje de inhibición de crecimiento radial (PICR) de acuerdo con Martínez y Solano (1994), utilizando la fórmula PICR = (R1 - R2) / $\mathrm{R} 1$ x 100 , donde $R 1$ es el radio del patógeno en la caja testigo y $R 2$ es el radio del patógeno en la 
Revista Iberoamericana de las Ciencias Biológicas y Agropecuarias

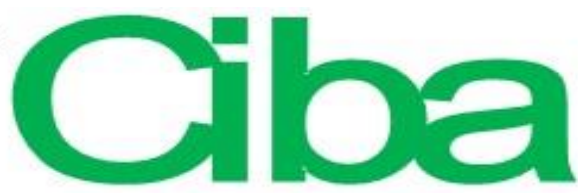

prueba antagónica en intervalos de 24 horas; las mediciones se detuvieron cuando la caja testigo quedó completamente cubierta por el hongo.

Las pruebas se hicieron con tres repeticiones por tratamiento y se comparó el valor final de porcentaje de inhibición para identificar si existieron diferencias significativas entre tratamientos. Esto mediante un análisis de la varianza (Anova) y una comparación de medias por el método de Tukey-Kramer a un $\alpha$ de 0.05 , después de haber verificado normalidad de datos.

\section{Resultados y discusión}

En la primera fase se aislaron e identificaron los organismos antagónicos nativos y el hongo fitopatógeno. Una vez verificada la identidad de los microorganismos, se procedió a realizar las distintas pruebas de inhibición.

\section{Aislamiento e identificación de microorganismos}

Las características macroscópicas y microscópicas de $P$. infestans aislada de cultivos infectados se muestran en la figura 1. El hongo cultivado en agar nutritivo presentó pigmentación cremosa, con zonaciones concéntricas y textura algodonosa. En los microcultivos se observaron características distintivas de la especie: hifas cenocíticas, oogonio, esporangióforo y los esporangios con presencia del pedicelo y la semipapila.

Figura 1. $P$. infestans aislado a partir de tejido de plantas de papa infectados cultivado en agar nutritivo (a), y en microcultivos que permiten observar las hifas cenocíticas 10x (b), esporangióforos 100x (c), y esporangios con pedicelo y semipapila 100x (d). Las barras corresponden a 10 micrómetros en 100x y 100 micrómetros en 10x

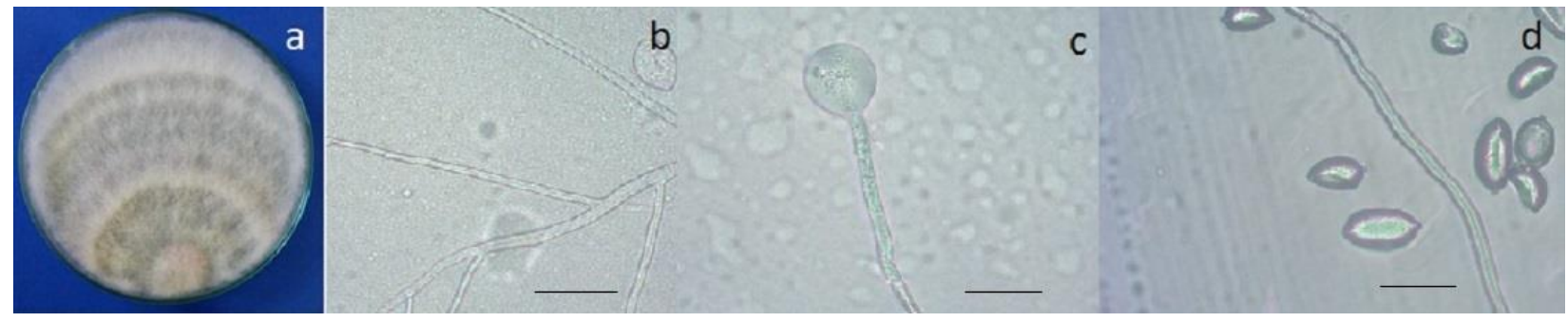

Fuente: Elaboración propia 
Revista Iberoamericana de las Ciencias Biológicas y Agropecuarias

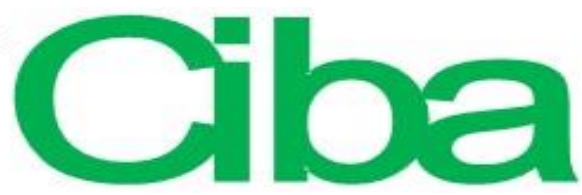

Se observó que las características morfológicas macro y microscópicas coinciden con las descripciones de Erwin y Ribeiro (1996).

Las características de la cepa nativa de Trichoderma sp. aislada a partir de suelo en la rizósfera de la solanácea silvestre de la localidad de Ixticpac, Zacapoaxtla, se muestra en la figura 2. Las colonias presentan color amarillo-verdoso después de 14 días de cultivo in vitro, forman anillos concéntricos de textura flocosa, con esporulación densa e incolora al anverso del inóculo.

Figura 2. Trichoderma sp. aislada a partir de suelo en la rizósfera de Solanum sp. silvestre de la localidad de Ixticpac, Zacapoaxtla, cultivado en PDA (a), los microcultivos que permiten observar los conidióforos y fiálides a 40x (b), y a 100x los conidios (c). Las barras corresponden a 10 micrómetros en 100x y 40 micrómetros en 40x

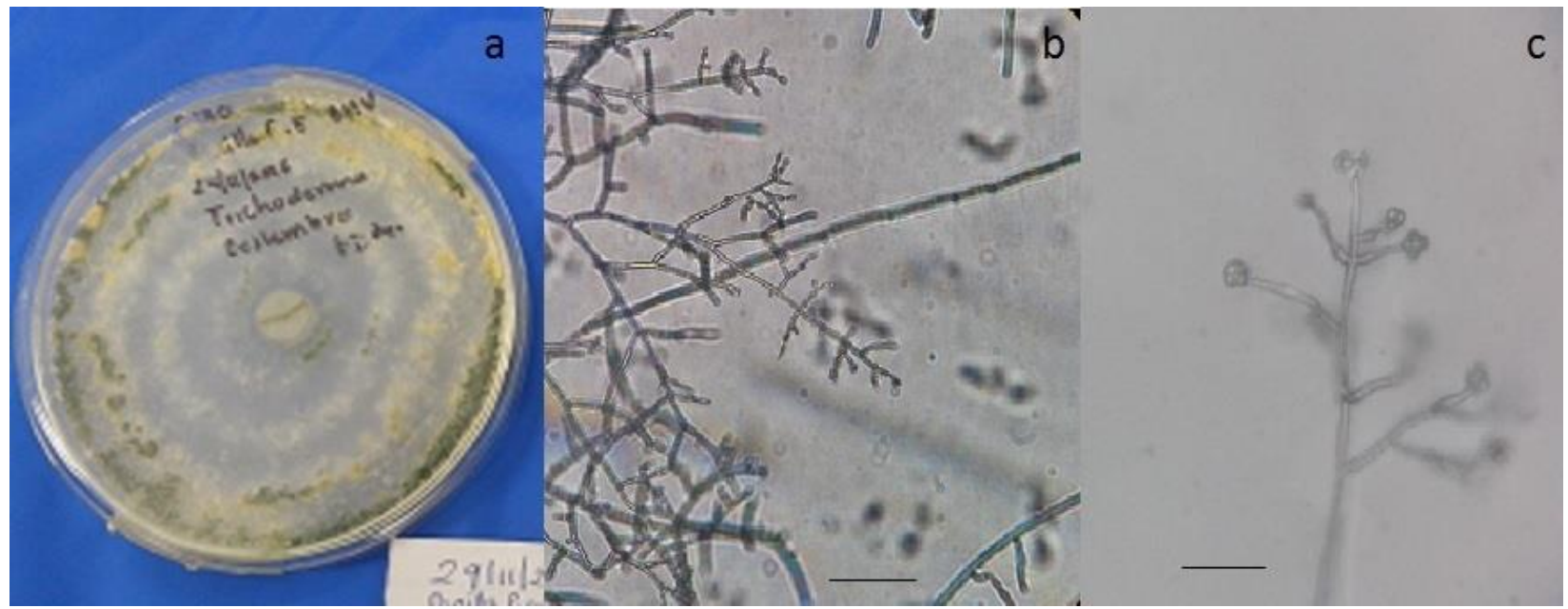

Fuente: Elaboración propia

La cepa aislada presenta hifas hialinas septadas, en los ejes centrales se originan los conidióforos ramificados con fiálides solitarias en forma de botellas alargadas, donde se encuentran lo conidios ovoides adheridos en forma de racimos. La disposición de la fiálides es opuesta o intercalada.

Los cultivos de bacterias aisladas a partir del suelo procedente de la rizósfera de la solanácea silvestre de la localidad de Ixticpac, Zacapoaxtla, fueron identificadas como Pseudomona sp. de acuerdo con las pruebas bioquímicas (tabla 1) y la tinción de Gram. 
Revista Iberoamericana de las Ciencias Biológicas y Agropecuarias

Tabla 1. Pruebas bioquímicas a Pseudomona sp. aisladas a partir del suelo procedente de la rizósfera de una solanácea silvestre de la localidad de Ixticpac, Zacapoaxtla

\begin{tabular}{|l|l|}
\hline Prueba & Código \\
\hline Tinción de Gram & - \\
\hline Crecimiento a $42{ }^{\circ} \mathrm{C}$ & - \\
\hline Crecimiento a $\mathrm{NaCl} 6.5 \%$ & - \\
\hline Catalasa & + \\
\hline Movilidad & + \\
\hline Glucosa oxidasa & + \\
\hline Lactosa-sacarosa-glucosa & + \\
\hline
\end{tabular}

Fuente: Elaboración propia

Cabe resaltar que las diferencias en cuanto a la localidad de donde fueron obtenidos los microorganismo antagonistas y los patógenos se debe a que en los campos de cultivo de papa en los que se detectó la presencia de tizón tardío no se localizaron solanáceas silvestres, y viceversa: no se observó presencia de $P$. infestans en los campos donde las solanáceas silvestres rodeaban el campo de cultivo.

\section{Pruebas de antagonismo}

Se observó antagonismo in vitro de Trichoderma sp. versus $P$. infestans. Las pruebas duales demuestran que Trichoderma inhibe el crecimiento de P. infestans más de $70 \%$ después de 250 horas (figura 3 ). 
Revista Iberoamericana de las Ciencias Biológicas y Agropecuarias

Figura 3. Inhibición in vitro de Trichoderma sp. sobre $P$. infestans vista del reverso (a) comparado con el testigo vista del anverso (b) cultivado en PDA, y monitoreando el porcentaje de inhibición durante 260 horas (c) a $28{ }^{\circ} \mathrm{C}$ en la oscuridad
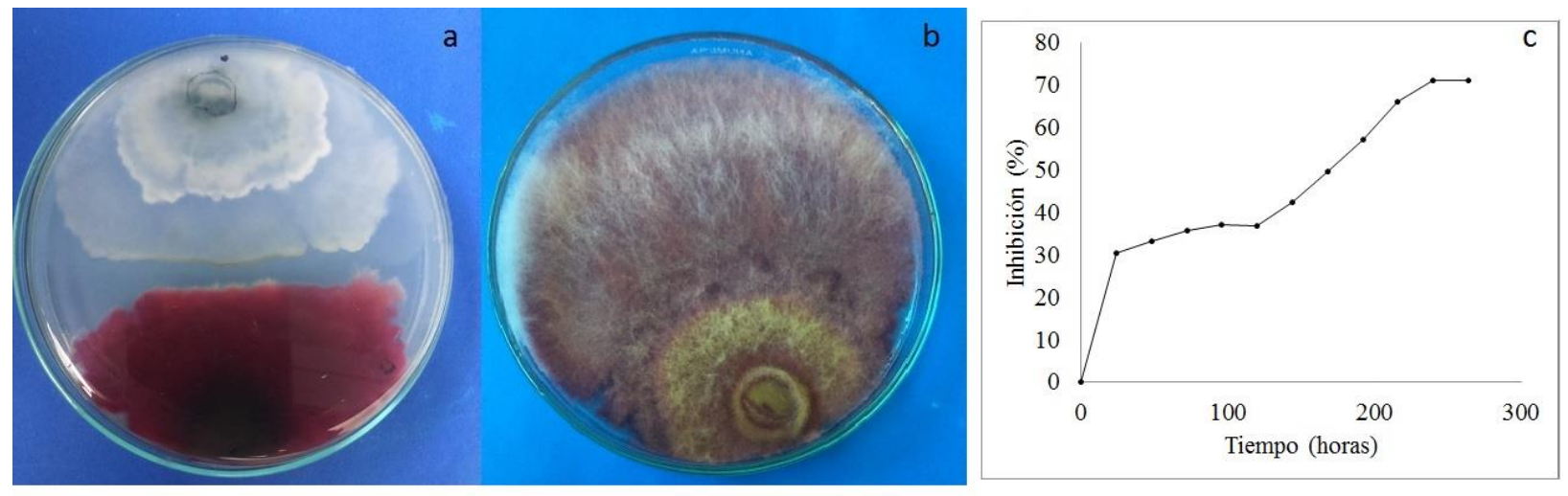

Fuente: Elaboración propia

De acuerdo con Bell et al. (1982, citado en Suárez y Cabrales, 2008), la capacidad antagónica de Trichoderma sp. fue de grado tres debido a que, después de 250 horas de incubación, el antagonista cubrió más de $50 \%$ de la superficie de la caja en presencia del patógeno. Se presentó una intensidad antagónica elevada puesto que $P$. infestans se inhibió más de $50 \%$. La forma de antagonismo es hiperparasitario, ya que existe un traslape de micelios, y el hongo antagonista cubre parte del parásito entrelazándolo. La interacción hifal es por enrollamiento (figura 4). 
Revista Iberoamericana de las Ciencias Biológicas y Agropecuarias

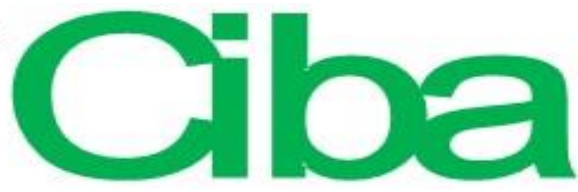

Figura 4. Microcultivo para evaluar el tipo de interacción antagonista entre Trichoderma sp. y $P$. infestans cultivado en PDA durante 96 horas a $28^{\circ} \mathrm{C}$ en la oscuridad, observadas en el microscopio óptico a 10x (a) y 100x (b)

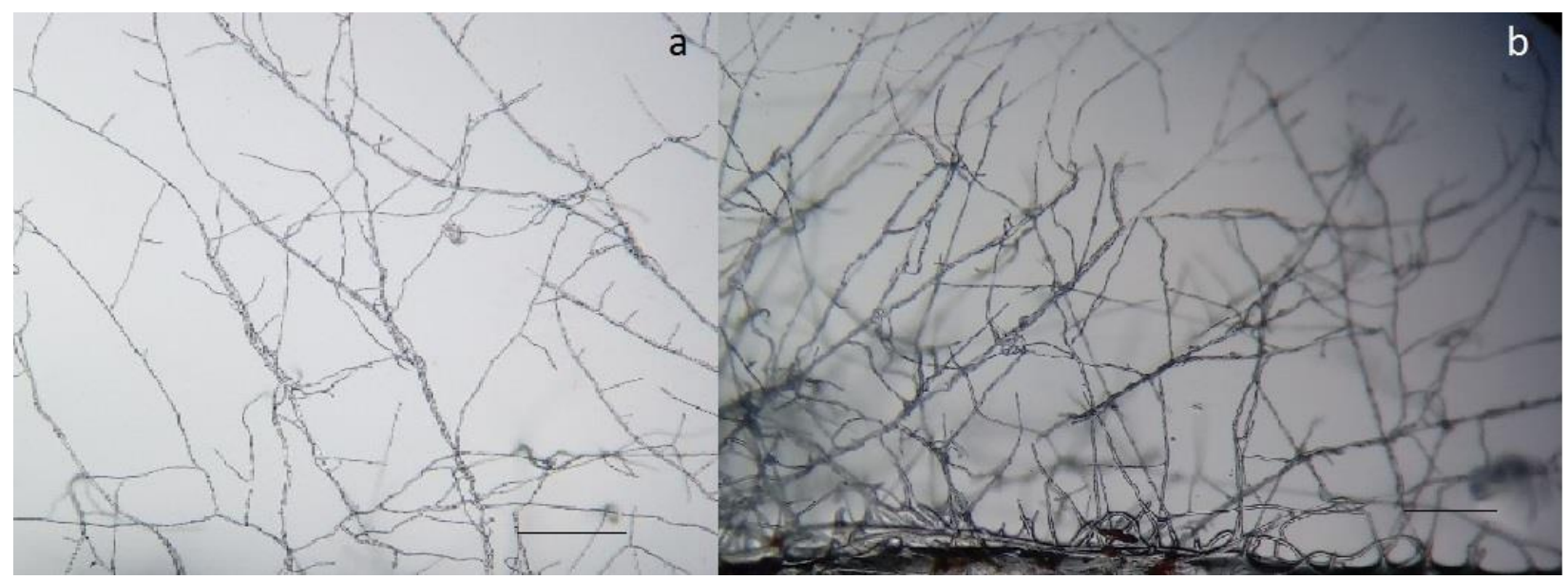

Fuente: Elaboración propia

En la prueba para evaluar el efecto indirecto ocasionado por Trichoderma sp. sobre el crecimiento de $P$. infestans se observó que existe inhibición desde el primer monitoreo a las 24 horas, y los valores oscilan entre $25 \%$ y $50 \%$ durante todo el tiempo que duró el experimento; a las 120 horas el fitopatógeno se inhibe $40 \%$ aproximadamente (figura 5).

Figura 5. Inhibición indirecta in vitro ocasionada por Trichoderma sp. sobre P. infestans comparado (a) con el testigo cultivados en PDA (b) y monitoreando del porcentaje de inhibición durante 120 horas (c) a $28{ }^{\circ} \mathrm{C}$ en la oscuridad. El microorganismo con coloración blanquecina corresponde al antagonista
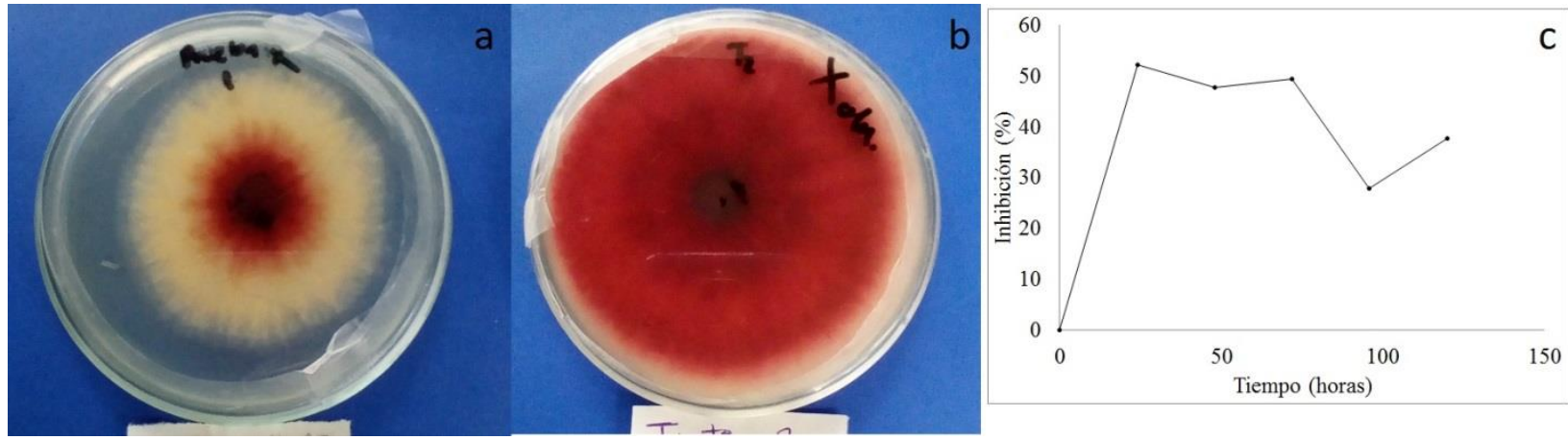

Fuente: Elaboración propia 
Revista Iberoamericana de las Ciencias Biológicas y Agropecuarias

La capacidad antagónica es de tres, ya que desde la primera evaluación (a las 24 horas) la inhibición es mayor a 50 \%. Kumar et al. (2015) evaluaron in vitro siete especies de Trichoderma (aisladas de diferentes localidades de Uttar Pradesh, al norte de la India) señaladas como silvestres por lo propios autores y obtenidas directamente del suelo; encontraron que todas son efectivas como antagonistas de diferentes fitopatógenos, pero el porcentaje de inhibición es diferente: Trichoderma reesei inhibe más de $60 \%$ a especies fitopatógenas de los géneros Alternaria Sclerotium y Bipolaris, mientras que Trichoderma viride inhibe más de $80 \%$ a $P$. infestans. Lo encontrado en este trabajo se acerca a los valores antes mencionados, ya que el hongo antagonista inhibe al fitopatógeno hasta $70 \%$ a las 260 horas de cultivo. La presencia de Pseudomona sp. en el mismo sistema de cultivo disminuye el crecimiento de $P$. infestans (figura $6)$.

Figura 6. Inhibición in vitro de Pseudomona sp. sobre $P$. infestans (a) comparado con el testigo cultivado en PDA (b) y monitoreando el porcentaje de inhibición durante 120 horas (c) a $28{ }^{\circ} \mathrm{C}$ en la oscuridad. El estriado blanquecino es el antagonista
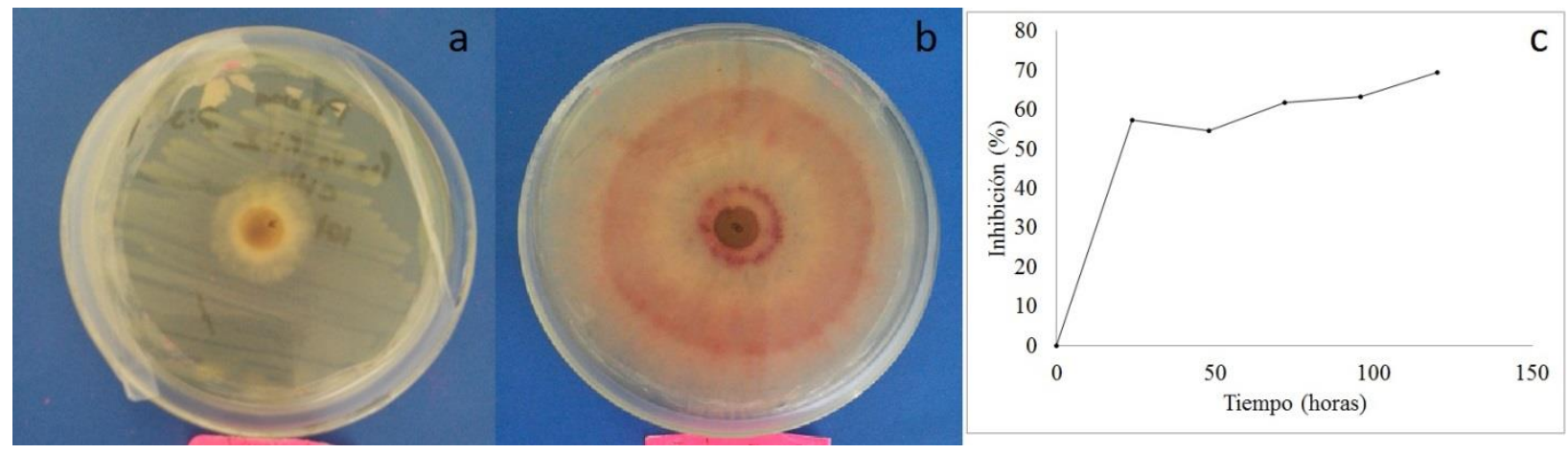

Fuente: original de los autores.

En la figura 7 se muestran los resultados de la evaluación in vitro del efecto inhibitorio de Pseudomona sp. y Trichoderma sp. sobre el crecimiento de P. infestans durante 168 horas. La presencia de la bacteria inhibe a los dos hongos sembrados, aparentemente Trichoderma no presentó crecimiento micelial, y la presencia de ambos antagonistas ocasiona que $P$. infestans se inhiba más de $80 \%$ a partir de las 120 horas, por lo que la capacidad antagónica es considerada de nivel cuatro. 
Revista Iberoamericana de las Ciencias Biológicas y Agropecuarias

Figura 7. Inhibición in vitro de Pseudomona sp. y Trichoderma sp. sobre P. infestans (a) comparado con el testigo (b) cultivado en PDA y monitoreando el porcentaje de inhibición durante 168 horas (c) a $28{ }^{\circ} \mathrm{C}$ en la oscuridad. El microorganismo estriado blanquecino es la bacteria
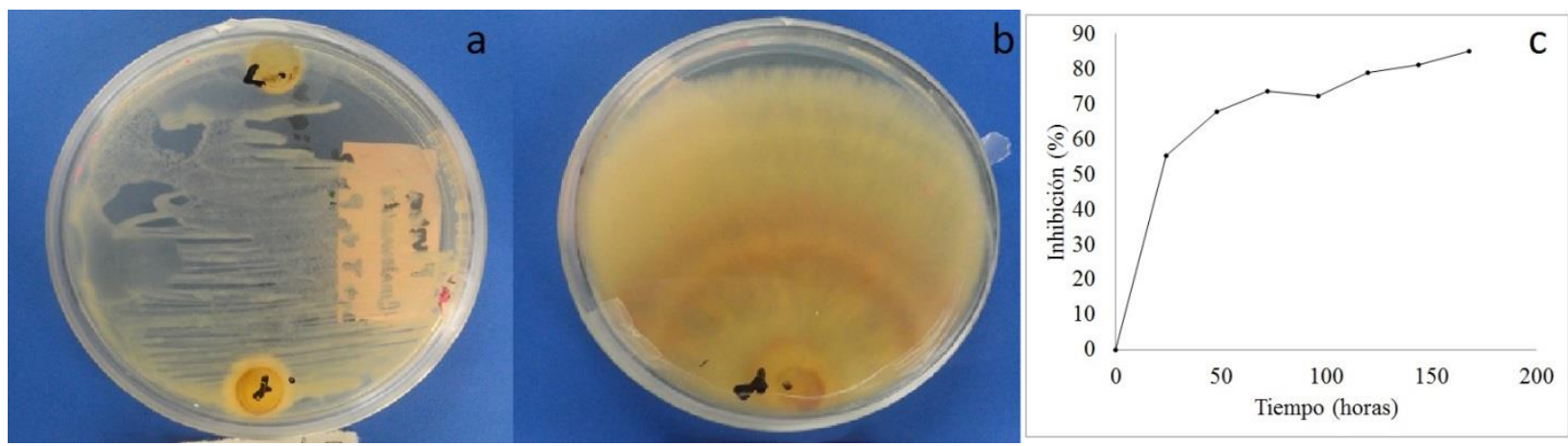

Fuente: Elaboración propia

La presencia de Pseudomona sp. en combinación con Trichoderma sp. hace más eficiente la inhibición de $P$. infestans que lo observado cuando está presente únicamente uno de los antagonistas (tabla 2), considerando que en 120 horas se inhibe $80 \%$ (valor que no se obtuvo en las otras pruebas); cuando los antagonistas nativos se encuentran en el sistema de cultivo de manera independiente se obtienen valores similares (alrededor de $55 \%$ ). No obstante, las cepas de Pseudomonas sp. no solamente contrarrestaron el crecimiento de P. infestans, también detuvieron el de Trichoderma sp. Probablemente se deba a la baja especificidad de los compuestos producidos por las bacterias; por ejemplo, se han detectado compuesto antifúngicos producidos por Pseudomona fluorescens que inhiben varias especies de Phytophthora, Rhizoctonia y Fusarium (Koche, Gade y Deshmukh, 2013). 
Revista lberoamericana de las Ciencias Biológicas y Agropecuarias

Tabla 2. Porcentaje de inhibición al final de cada una de las pruebas en las que se evaluó el antagonismo de Trichoderma sp. (en contacto directo e interacción indirecta), Pseudomona sp. y la combinación Trichoderma-Pseudomona (silvestres) sobre P. infestans. Las letras representan diferencias significativa $(\alpha=0.05)$ entre promedios del porcentaje de inhibición con tres repeticiones, de acuerdo con un Anova y una comparación de medias por Tukey-Kramer

\begin{tabular}{|l|c|c|}
\hline Tratamiento & Inhibición (\%) & Tiempo (horas) \\
\hline Trichoderma sp. en contacto directo & $71 \mathrm{~b}$ & 264 \\
\hline Trichoderma sp. interacción indirecta (volátiles) & $38^{\mathrm{a}}$ & 120 \\
\hline Pseudomona sp. & $69 \mathrm{~b}$ & 120 \\
\hline Trichoderma sp.-Pseudomona sp. & $85 \mathrm{c}$ & 168 \\
\hline
\end{tabular}

Fuente: original de los autores.

La diferencia en los porcentajes de inhibición de $85 \%$ al final de monitoreo sobre el fitopatógeno cuando están presentes los dos microorganismos antagonistas, en comparación con lo obtenido con los microorganismos individualmente (de $69 \%$ a $71 \%$ ), sugiere la producción de compuestos producidos por el hongo antagonista que contribuyen a la disminución indirecta del crecimiento de P. infestans. Debido a que la bacteria también inhibió a Trichoderma y no existió contacto micelial como en el caso de las pruebas utilizando solamente el hongo antagonista. ElHasan, Walker, Schöne y Buchenauer (2009) encontraron metabolitos secundarios volátiles producidos por Trichoderma que inhiben el crecimiento de hongos fitopatógenos como Fusarium.

En cuanto a la inhibición in vitro de $P$. infestans por los microorganismos nativos, de forma individual se determinó que Trichoderma harzianum inhibe in vitro $86 \%$ al fitopatógeno por competencia y colonización (Fatima, Noureddine, Henni y Mabrouk, 2015), mientras que el mismo efecto inhibitorio fue observado por la inoculación combinada de diferentes cepas pertenecientes al género Pseudomona (De Vrieze et al., 2018). Asimismo, Zegeye, Santhanam, Gorfu, Tessera y Kassa, 2011) encontraron que especies de los géneros Trichoderma y Pseudomona son una alternativa en el control del tizón tardío en papa; no obstante, dicho estudio indica que los microorganismos al ser inoculados de manera individual son más efectivos que cuando fueron añadidos de manera simultánea, contrario a lo encontrado en este estudio, ya que al parecer existe un sinergismo bacteria-hongo para inhibir al patógeno en condiciones in vitro. Lo anterior sugiere que la presencia del suelo de ambos antagonistas son una alternativa para 
Revista Iberoamericana de las Ciencias Biológicas y Agropecuarias

disminuir el impacto del tizón tardío en los cultivos de papa, inoculando dichos microorganismos para asegurar la presencia y densidad efectiva.

Se considera que deben realizarse pruebas en condiciones regulares de cultivo para diseñar una estrategia que permita la utilización de microorganismos nativos presentes en los suelos de la región para disminuir la incidencia de hongos dañinos como el que ocasiona el tizón tardío.

\section{Conclusiones}

Los microorganismos nativos pertenecientes a los géneros Pseudomona y Trichoderma aislados de la rizósfera de una solanácea silvestre localizada en las inmediaciones de campos de cultivo de papa (Solanum tuberosum) inhiben el crecimiento in vitro de $P$. infestans procedente de una plantación infectada de tizón tardío.

La disminución del crecimiento se presenta al estar en contacto directo fitopatógenoantagonista, o bien, indirectamente en el caso del hongo antagonista.

Los resultados sugieren que existe un efecto sinérgico hongo-bacteria, ya que la inhibición es porcentualmente mayor cuando están presentes simultáneamente los dos organismos en comparación con la inoculación individual; en todos los casos fue mayor a $60 \%$ excepto en el caso de la inhibición indirecta ocasionada por Trichoderma sp. 
Revista Iberoamericana de

las Ciencias Biológicas

y Agropecuarias

\section{Referencias}

Aguado, G. A., Rascón, R., y Luna, A. (2012). Impacto económico y ambiental del empleo de fertilizantes químicos. Ciudad de México, México: Inifap/Sagarpa.

Altieri, M. A. y Nicholls, C. (2008). Optimizando el manejo agroecológico de plagas a través de la salud del suelo. Agroecología, 1, 29-36.

Badii, M. y Varela, S. (2015). Insecticidas Organofosforados: Efectos sobre la Salud y el Ambiente. Cultura Científica y Tecnológica, 5(28), 5-17. Recuperado de http://erevistas.uacj.mx/ojs/index.php/culcyt/article/view/375.

Bell, D. K., Wells, H. D. y Markaman, C. R. (1982). In Vitro Antagonism of Trichoderma spp. Against Six Fungal Pathogens. Phytopathology, 72, 379-382.

Borba, N. (2008). La papa, un alimento básico. Posibles impactos frente a la introducción de papa transgénica. Montevideo, Uruguay: RAP-AL Uruguay.

Burkholder, W. H. (1957). Bergey's Manual of Determinative Bacteriology. Maryland, United States: The Williams \& Wilkins Company.

Cano, M. A. (2011). Interacción de microorganismos benéficos en plantas: micorrizas, Trichoderma spp. y Pseudomonas spp. una revisión. Revista UDCA Actualidad \& Divulgación Científica, 14(2), 15-31.

Davet, P., Artigues, M. y Martin, C. (1981). Production en conditions non aseptiques d'inoculum de Trichoderma harzianum Rifai pour des essais de lutte biologique. Agronomie, 1(10), 933-936.

Dennis, C. y Webster, J. (1971) Antagonistic properties of species group of Trichoderma II production of Non-volatile antibiotics. Transactions of the British Mycology Society, $57(1), 41-48$.

De Vrieze, M., Germanier, F., Vuille, N. and Weisskopf, L. (2018). Combining different potatoassociated Pseudomonas strains for improved biocontrol of Phytophthora infestans. Frontiers in Microbiology, 9, 1-13. doi: 10.3389/fmicb.2018.02573

El-Hasan, A., Walker, F., Schöne, J. y Buchenauer, H. (2009). Detection of viridiofungin A and other antifungal metabolites excreted by Trichoderma harzianum active against different plant pathogens. European Journal of Plant Pathology, 124(3), 457-470.

Erwin, D. C. y Ribeiro, O. K. (1996). Phytophthora diseases worldwide. Minnesota, United States: American Phytopathological Society Press. 
Revista Iberoamericana de

las Ciencias Biológicas

y Agropecuarias

ISSN: 2007 - 9990

Fatima, K., Noureddine, K., Henni, J. E. and Mabrouk, K. (2015). Antagonistic effect of Trichoderma harzianum against Phytophthora infestans in the North-west of Algeria. International Journal of Agronomy and Agricultural Research, 6(4), 44-53.

Fernández, S. P., Rodríguez, G., Garay, E., Belmar, C. R., Sturbaum, K., Flier, W. y Lozoya, H. (2005). Caracterización de Aislamientos de Phytophthora infestans (Mont.) de Bary provenientes de Michoacán, México. Revista Mexicana de Fitopatología, 23(2), 191-197.

García, H. G., Martínez, Á. R., Hermosa, M. R., Monte, E., Aguilar, C. J. y González, C. E. (2017). Caracterización morfológica y molecular de cepas nativas de Trichoderma y su potencial de biocontrol sobre Phytophthora infestans. Revista Mexicana de Fitopatología, 35(1), 58-79.

González, J. M. y Reséndiz, V. H. (2012). Uso de Trichoderma como agente de crecimiento vegetal. En Aguado, A. (ed.). Introducción al uso y manejo de los biofertilizantes en la agricultura (pp. 195-218). Celaya, México: Inifap-Sagarpa.

Helguero, E. T. (2010). Bacilos gram negativos no fermentadores: Pseudomonas, Stenotrophomonas, Acinetobacter, Burkholderia. Vigilancia, Prevención y Control de Infecciones Asociadas a los Servicios de Salud, 1(1), 319-340.

Hernández, A., Heydrich, M., Velázquez, M. G. y Hernández, A. N. (2006). Perspectivas del empleo de rizobacterias como agentes de control biológico en cultivos de importancia económica. Revista Mexicana de Fitopatología, 24(1), 42-49.

Kim, H. S., Park, J., Choi, K. H., Lee, G. P., Ban, S. J., Lee. C. H. y Kim, C. S. (2003). Isolation and characterization of Bacillus strains for biological control. Journal of Microbiology, 41(3), 196-201.

Koche, M. D., Gade, R. M. y Deshmukh, A. G. (2013). Antifungal activity of secondary metabolites produced by Pseudomonas fluorescens. The Bioscan, 8(2), 723-726.

Kubicek, C. P. y Harman, G. E. (1998). Trichoderma \& Gliocladium. Volume 1: Basic Biology, Taxonomy and Genetics. Abingdon, United States: Taylor and Francis Ltd.

Kumar, V., Shahid, M., Srivastava, M., Singh, A., Pandey, S. y Maurya, M. K. (2015). Screening of Trichoderma species for virulence efficacy on seven most predominant phytopathogens. African Journal of Microbiology Research, 9(11), 793-799.

Martínez, B. y Solano, T. (1994) Antagonismo de Trichoderma spp. frente a Alternaria solani (Ellis y Martin) Jones y Grout. Revista Protección Vegetal, 10(3), 221-225. 
Revista Iberoamericana de

las Ciencias Biológicas

y Agropecuarias

ISSN: 2007 - 9990

Martínez, E. P. y Osorio, J. A. (2007). Estudios preliminares para la producción de un biosurfactante bacteriano activo contra Phytophthora infestans (Mont.) De Bary. Corpoica Ciencia y Tecnología Agropecuaria, 8(2), 5-16.

Paucarima, A. F., Egúsquiza, R. M., Patiño, A., Sánchez, T. L., Alcarraz, M., Claudio, J., Trigoso, C. y Evangelio, A. (2014). Selección evaluación de microorganismos nativos con potencial antagonista de Rhizoctonia solani y Phytopthora infestans promotores del crecimiento de tuberculillos de papa Solanum tuberosum L. in vitro. Theorèma, l(1), 2736.

Pérez, W., y G. Forbes. (2008). Manual técnico. El Tizón tardío de la papa. Lima, Perú: Potato International Center.

Puño, R., Terrazas, E., Alvares, T., Giménez, A., Mendoza, L., Smeltekop, H., y Loza, M. (2011). Evaluación de la capacidad biocontroladora de metabólicos de Trichoderma inhamatum Bol12 QD sobre cepas nativas de Phytophthora infestans in vitro. Journal of the Selva Andina Research Society, 2(1), 26-33.

Suárez, L. Y. y Cabrales, C. P. (2008). Identificación de especies de cepas nativas de Trichoderma sp. y Bacillus sp. y evaluación de su potencial antagonista in vitro frente al hongo fitopatógeno nativo Moniliophthora roreri en el departamento de Norte de Santander. Respuestas, 13(1), 45-56.

Riddell, R. W. (1950). Permanent strained mycological preparation obtained by slide cultures. Mycologia, 42(2), 265-270.

Romero, G., Lozoya, H., Mora, G., Fernández, S. y Grünwald, N. J. (2012). Rendimiento de papa en función de epidemia por tizón tardío (Phytophthora infestans Mont. de Bary). Revista Fitotecnia Mexicana, 35(1), 69-78.

Zegeye, E. D., Santhanam, A., Gorfu, D., Tessera, M., y Kassa, B. (2011). Biocontrol activity of Trichoderma viride and Pseudomonas fluorescens against Phytophthora infestans under greenhouse conditions. Journal of Agricultural Technology, 7(6), 1589-1602. 
Revista Iberoamericana de las Ciencias Biológicas

y Agropecuarias

\begin{tabular}{|l|l|}
\hline Rol de Contribución & Autor (es) \\
\hline Conceptualización & Citlalli Harris Valle \\
\hline Metodología & Efren Bonilla pioquinto \\
\hline Software & NO APLICA \\
\hline Validación & Martín Palafox Rodríguez \\
\hline Análisis Formal & NO APLICA \\
\hline Investigación & Citlalli Harris Valle \\
\hline Recursos & Martín Palafox Rodríguez \\
\hline Curación de datos & Citlalli Harris Valle \\
\hline $\begin{array}{l}\text { Escritura - Preparación del } \\
\text { borrador original }\end{array}$ & Citlalli Harris Valle \\
\hline $\begin{array}{l}\text { Escritura - Revisión y } \\
\text { edición }\end{array}$ & Citlalli Harris Valle \\
\hline Visualización & Citlalli Harris en colaboración con Martín Palafox \\
\hline Supervisión & Citlalli Harris en colaboración con Efrén Bonilla \\
\hline $\begin{array}{l}\text { Administración de } \\
\text { Proyectos }\end{array}$ & Martín Palafox en coordinación con Citlalli Harris \\
\hline Adquisición de fondos & Citlalli Harris \\
\hline
\end{tabular}

